\title{
APPLICATION OF GUIDED WAVE PROPAGATION IN DIAGNOSTICS OF STEEL BRIDGE COMPONENTS
}

\author{
M. RUCKA ${ }^{1}$, B. ZIMA ${ }^{2}$, R. KĘDRA ${ }^{3}$
}

\begin{abstract}
Early detection of potential defects and identification of their location are necessary to ensure safe, reliable and long-term use of engineering structures. Non-destructive diagnostic tests based on guided wave propagation are becoming more popular because of the possibility to inspect large areas during a single measurement with a small number of sensors. The aim of this study is the application of guided wave propagation in non-destructive diagnostics of steel bridges. The paper contains results of numerical analyses for a typical railway bridge. The ability of damage detection using guided Lamb waves was demonstrated on the example of a part of a plate girder as well as a bolted connection. In addition, laboratory tests were performed to investigate the practical application of wave propagation for a steel plate and a prestressed bolted joint.
\end{abstract}

Keywords: non-destructive testing, damage detection, condition assessment, guided wave propagation, steel bridges

\section{INTRODUCTION}

Engineering structures undergo the process of gradual destruction in the course of time as a result of static and dynamic loading, temperature, humidity, wind or corrosive factors. Early detection of potential defects and identification of their location are necessary to ensure safety of structures. Great significance of bridge structures results in high requirements for their reliable and long-term use. In consequence many diagnostic techniques [1] and structural health monitoring (SHM) systems [2] have been developed and investigated for bridge structures over last years. Guided wave propagation methods play a significant role in damage detection strategies. In wave propagation techniques a structure can be perceived as a waveguide, which directs the energy along

1 Department of Structural Mechanics, Faculty of Civil and Environmental Engineering, Gdańsk University of Technology, Narutowicza 11/12, Gdańsk, Poland, email: mrucka@pg.gda.pl

2 Department of Structural Mechanics, Faculty of Civil and Environmental Engineering, Gdańsk University of Technology, Narutowicza 11/12, Gdańsk, Poland, email: beazima@pg.gda.pl

3 Department of Metal Structures and Management in Civil Engineering, Faculty of Civil and Environmental Engineering, Gdańsk University of Technology, Narutowicza 11/12, Gdańsk, Poland, email: rafkedra@pg.gda.pl 
its length. Guided waves have ability of propagation over relatively long distances with little energy loss. Diagnostic methods based on guided waves propagation phenomenon offer the advantage of being adapted to the automated inspection of large areas with a small number of sensors. That is the reason why methods based on wave propagation are very promising solutions referring to advanced monitoring systems. Guided waves are very suitable for evaluation of structural elements of steel and composite bridges, in particular plain girders as well as welded, bolted and adhesive joints [3], [4], [5].

Wave propagation-based damage detection methods have been the subject of intensive studies over several last decades. Guided waves have been successfully used for detecting defects in simple steel structures such rods, beams, frames, plates or plain joints (e.g. [6], [7], [8]). Two approaches of damage detection strategies can be distinguished: the pulse-echo method and the pitch-catch method. In the pulse-echo method, structural defects are detected in the form of additional echoes in registered signals based on the value of the time-of-flight that can be defined as the time interval between the incident wave and the wave reflected from damage. For the known group velocity of the propagating wave, the time-of-flight is used to determine relative distances between damage, an excitation point and a registration point. Based on a certain number of registered signals, the difference in the time-of-flight between the wave reflected from damage and the extracted incident wave can be calculated and then damage can be triangulated. The number of signals which is necessary to obtain unambiguous results of damage localization depends on the type of testing structure. For one-dimensional elements (beam, rod) only one signal let to find accurate position of damage [6]. In the case of two-dimensional elements (e.g. plate girders) for each pair excitation point/ registration point an infinite number of possible damage locations exists and that is the reason why more than one pair of excitation point/registration point is necessary. After defining the damage index, the results of such analysis for a plate can be presented in the form of maps (e.g. [9], [10]). The second damage detection approach, called the pitch-catch method, utilizes the phenomenon of energy dissipation. The measuring system generally consists of one actuator and one sensor, which are located on two sides of a monitored element. Detection of failure is based on qualitative and quantitative changes occurring in guided Lamb waves travelling through a damaged area (e.g. [11], [12], [13]).

The study deals with application of guided wave propagation in non-destructive diagnostics of steel bridge. The paper contains results of numerical analyses for a railway bridge. The ability of damage detection using guided Lamb waves was demonstrated on the example of a part of a plate girder as well as a bolted connection. In addition, laboratory tests were performed to investigate the practical application of wave propagation for a steel plate and a prestressed bolted joint. 


\section{Theoretical BaCKGround of LAMB WAVE PROPAGATION}

Elastic waves are disturbances that propagate from one region of space to another. They are an effect of volume and shape deformation of a medium and they are caused by external forces called waves sources. Elastic wave propagation is associated with the movement of medium particles increasingly distant from the wave source. The character of wave propagation strongly depends on restrictions imposed on the elastic medium. In unbounded elastic media two types of bulk waves can propagate: longitudinal and shear waves. Interaction of bulk waves with a boundary results in creation of another type of waves, called guided waves. Lamb waves are a type of elastic, guided waves propagating in solids which are limited in one direction by two parallel surfaces, where the distance between surfaces is comparable with the wavelength, and does not exceed few wavelengths. Lamb waves can exist in two types of modes: symmetric $\left(\mathrm{S}_{0}, \mathrm{~S}_{1}, \mathrm{~S}_{2}, \ldots\right)$ and antisymmetric $\left(\mathrm{A}_{0}, \mathrm{~A}_{1}, \mathrm{~A}_{2}, \ldots\right)$. At the lowest frequency, two basic (zero-order) modes $\mathrm{S}_{0}$ and $\mathrm{A}_{0}$ can simultaneously exist (Figure 1). With the increase of frequency, higher modes appear and in general, infinite number of modes is associated with a guided Lamb wave problem.

a)

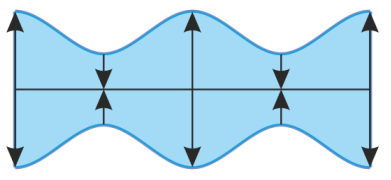

b)

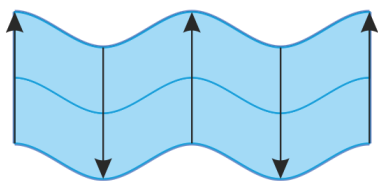

Fig. 1. Lamb wave modes: a) symmetric $\mathrm{S}_{0} ; \mathrm{b}$ ) antisymmetric $\mathrm{A}_{0}$

Interaction of Lamb waves with boundaries causes dispersive nature of Lamb waves, i.e. their velocity is frequency dependent. To determine dispersion relation, the Rayleigh-Lamb frequency equations can be used, determined for symmetric and antisymmetric modes, respectively [14]:

$$
\begin{aligned}
& \frac{\tan (q d)}{\tan (p d)}=-\frac{4 k^{2} p q}{\left(q^{2}-k^{2}\right)^{2}}, \\
& \frac{\tan (q d)}{\tan (p d)}=-\frac{\left(q^{2}-k^{2}\right)^{2}}{4 k^{2} p q} .
\end{aligned}
$$

These equations describe relationship between the wave velocity and the frequency of propagating waves within a plate of thickness $h=2 d$. Parameter $k$, called the wavenumber, can be interpreted as the spatial frequency of the wave: 


$$
k=\frac{2 \pi}{\lambda}=\frac{\omega}{c_{p}},
$$

where $\omega$ is the circular frequency, $\lambda$ is the wavelength which refers to the spatial period of the wave, and $c_{p}$ denotes the phase velocity. The group velocity $c_{g}$ is the velocity at which the wave packet propagates and it is defined as:

$$
c_{g}=\frac{d \omega}{d k} .
$$

The variables $q$ and $p$ are given by:

$$
\begin{aligned}
& p^{2}=\frac{\omega^{2}}{c_{L}^{2}}-k^{2}, \\
& q^{2}=\frac{\omega^{2}}{c_{T}^{2}}-k^{2},
\end{aligned}
$$

where $c_{L}$ and $c_{T}$ are speeds of longitudinal and transverse wave, respectively:

$$
c_{L}=\sqrt{\frac{E(1-v)}{\rho(1+v)(1-2 v)}},
$$

$$
c_{T}=\sqrt{\frac{E}{2 \rho(1+v)}} .
$$

The solutions of the Rayleigh-Lamb transcendental equations are not straightforward, because of dependence of $q$ and $p$ on the wavenumber $k$. Solutions of these equations can be presented as so called dispersion curves. Group velocity dispersion curves for a steel plate of thickness $d=16 \mathrm{~mm}$ are presented in Figure 2. It can be seen that in the range from $0 \mathrm{kHz}$ to $100.2 \mathrm{kHz}$ only two fundamental modes exist. Above 100.2 $\mathrm{kHz}$ the antisymmetric mode $\mathrm{A}_{1}$ appears, while the symmetric mode $\mathrm{S}_{1}$ appears above $174.4 \mathrm{kHz}$. The knowledge of dispersion curves enables a proper choice of the frequency of the excited wave for damage detection purposes. The frequency of the input wave should not exceed the frequency where the second mode appears. 


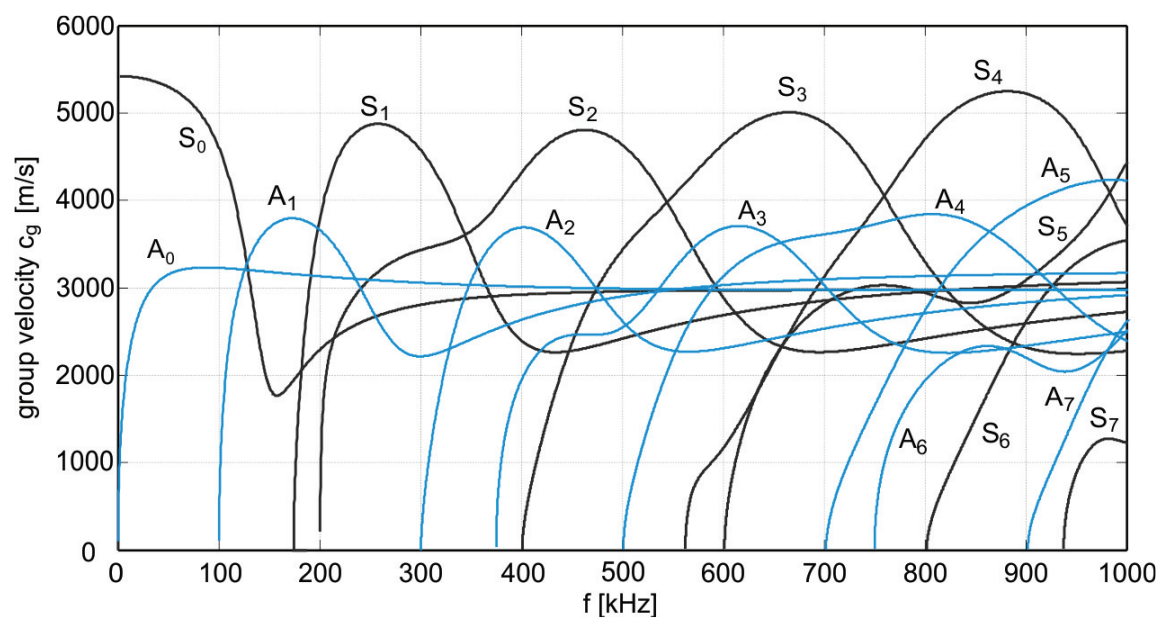

Fig. 2. Group velocity dispersion curves for steel plate of thickness $d=16 \mathrm{~mm}$ $\left(E=210 \mathrm{GPa}, \rho=7850 \mathrm{~kg} / \mathrm{m}^{3}, v=0.3\right)$

\section{Feasibility CASE STUdy}

\subsection{DesCriPTION OF BRIDGE STRUCTURE}

In order to verify the possible use of diagnostic methods based on guided wave propagation to bridge structures, numerical analysis by the finite element method (FEM) has been performed. One section of a typical through plate girder railway bridge with the open road was investigated. The geometry of the model is shown in Figure 3. It consists of the main girder with a length of $4000 \mathrm{~mm}$ which is connected in the middle of the span to the cross beam with a length of $2000 \mathrm{~mm}$. In the place of their connection stiffening plates are applied. The longitudinal member is situated in parallel with the main girder at a distance of $1050 \mathrm{~mm}$ from it. All these elements were designed as I-beams composed of plates of dimensions given in Table 1. The connections between the web and flanges were performed as welded with fillet welds. The wind bracing is connected to the main girder and the cross beam by a gusset plate. The splice is symmetric with respect to the vertical axis and it consists of 7 steel cover plates and 56 prestressed bolts with a diameter of $20 \mathrm{~mm}$. In the vertical part of the joint the connectors are arranged in 7 rows and 4 columns. The examined joint of the web and flanges of the cross beam was designed as a double lap connection of class $\mathrm{C}$ (slip-resistant at ultimate limit state) and bolts are class 8.8 [15]. All other connections i.e. the connection of the longitudinal member with the cross beam or the connection of the stiffening plate with the main girder and the cross beam are designed as welded joints. 
Table 1

Cross sectional dimensions of analysed bridge components

\begin{tabular}{|c|c|c|c|c|}
\hline \multirow{2}{*}{ Bridge components } & \multicolumn{2}{|c|}{ Web } & \multicolumn{2}{c|}{ Flanges } \\
\cline { 2 - 5 } & Height $[\mathrm{mm}]$ & $\begin{array}{c}\text { Thickness } \\
{[\mathrm{mm}]}\end{array}$ & Width [mm] & $\begin{array}{c}\text { Thickness } \\
{[\mathrm{mm}]}\end{array}$ \\
\hline Main girder & 2000 & 16 & 450 & 30 \\
\hline Cross beam & 850 & 10 & 220 & 20 \\
\hline Longitudinal member & 530 & 14 & 200 & 20 \\
\hline
\end{tabular}

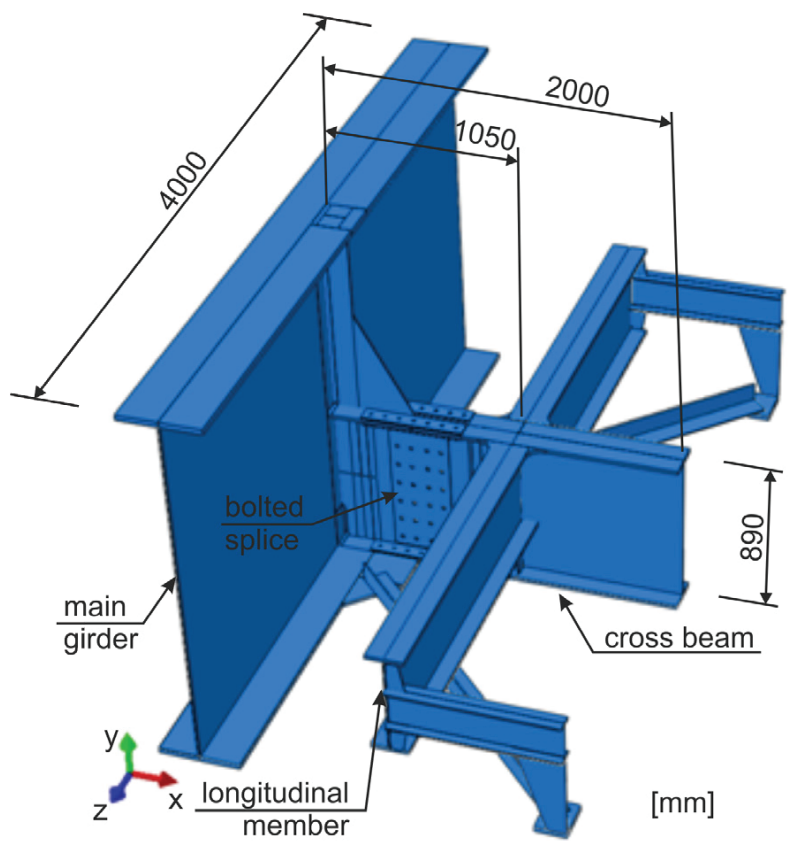

Fig. 3. Considered fragment of steel railway bridge

\subsection{Damage SCEnARios}

Two the most typical damage scenarios of the bridge girder were considered: damage of the plate girder because of the occurrence of corrosion and the reduction of the load capacity of the bolted splice due to the bolt loosening or fracture of fasteners in the threaded area. Damage of the plate girder was considered as a long notch through the plate with a relatively small surface area according to the girder area. The defect with dimensions $50 \mathrm{~mm} \times 10 \mathrm{~mm}$ was located $250 \mathrm{~mm}$ from the plate edge (Figure 4). 
For the bolted joint seven scenarios of damage were examined. A detailed list of considered scenarios of fasteners failure is given in Table 2 and the numbering of bolts is shown in Figure 5. Scenario \#1 was a pristine joint. In scenarios \#2 to \#7 loosening of a single fastener was analysed. In damage scenarios \#2 to \#5 fasteners on the horizontal axis of bolted splice were removed. In damage scenarios \#6 to \# 7 loosening of fasteners from the column closest to the main girder was simulated.

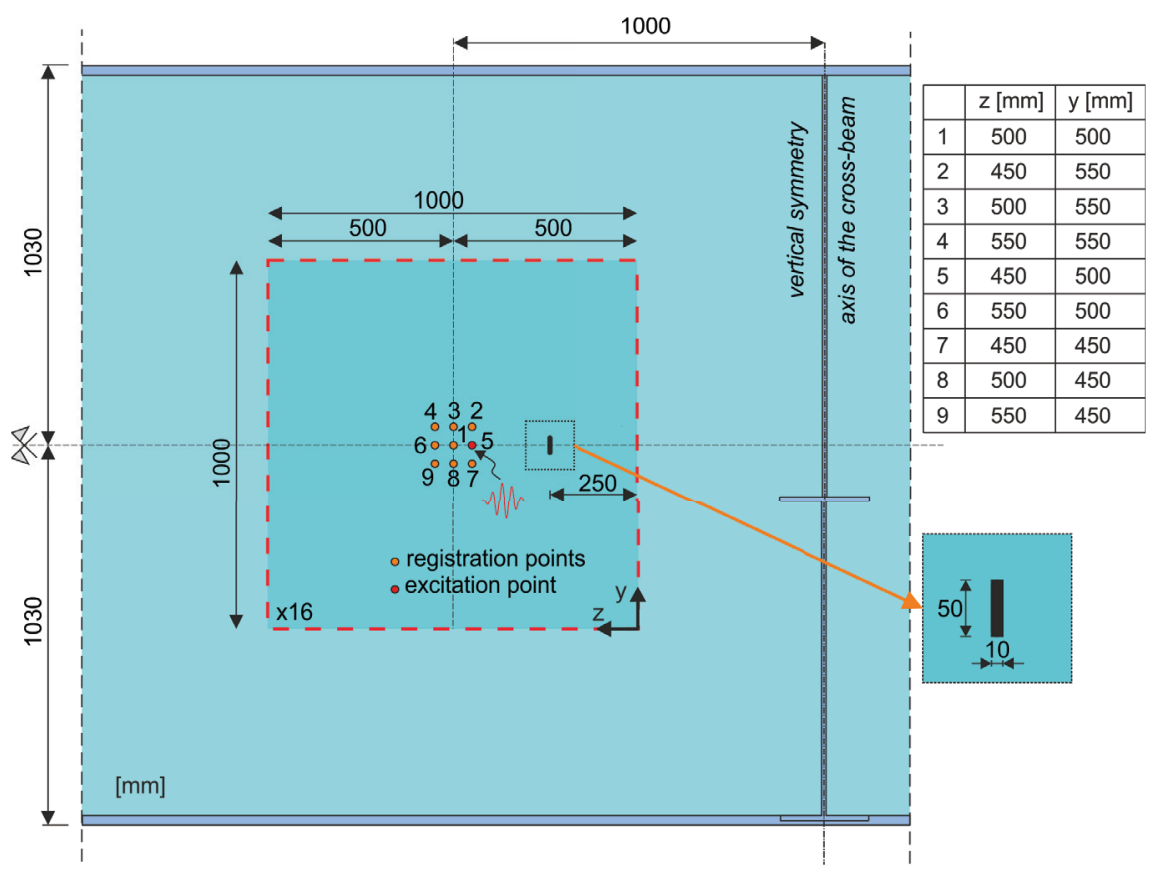

Fig. 4. Geometry of investigated part of plate girder

Table 2

Damage scenarios of bolted splice connection

\begin{tabular}{|c|c|}
\hline Damage scenario & Removed bolts \\
\hline$\# 1$ (pristine joint) & none \\
\hline$\# 2$ & $\mathrm{~S} 13$ \\
\hline$\# 3$ & $\mathrm{~S} 14$ \\
\hline$\# 4$ & $\mathrm{~S} 15$ \\
\hline$\# 5$ & $\mathrm{~S} 16$ \\
\hline$\# 6$ & $\mathrm{~S} 17$ \\
\hline$\# 7$ & $\mathrm{~S} 21$ \\
\hline
\end{tabular}




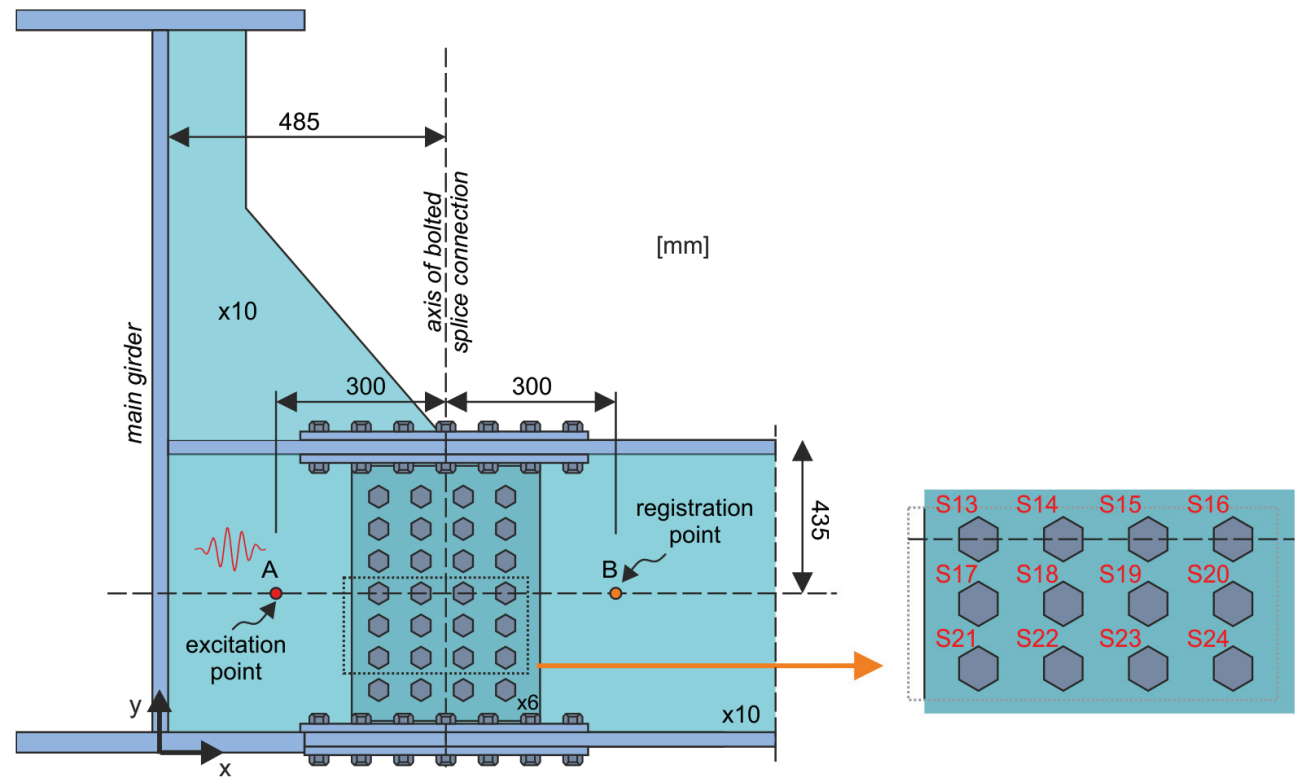

Fig. 5. Geometry of investigated bolted splice connection

\subsection{FEM MODEL FOR WAVE PROPAGATION}

Numerical model was developed by the FEM commercial program Abaqus /Explicit. To reduce the computation cost several simplifications were introduced. All parts beyond fasteners were modelled using two-dimensional, three-node and four-node shell elements with reduced integration (S3R, S4R). The maximum size of elements was assumed as $2 \mathrm{~mm}$. All bolt studs were modelled by ten two-node beam elements (B31). Connection of bolts and plates was made as kinematic coupling between end or middle node of the fastener and nodes at the edge of the hole. Contact between the web and overlay plates was not taken into account. It was caused by the fact that only two scenarios: correct operation or complete loosening of bolt were considered in the analysis. In order to increase the accuracy of calculations hourglass control was introduced.

The material of the testing structure was assumed to have linear elastic behaviour with density $\rho=7850 \mathrm{~kg} / \mathrm{m}^{3}$, Young modulus $E=210 \mathrm{GPa}$ and Poisson's ratio v $=0.3$. Damping was not taken into account during numerical investigations. Damage in the girder was modelled by removing of finite elements within the notch area (Figure 4) and bolt loosening was realized by removing of constrains between fasteners and plates. The excitation was realized in the form of five cycles of sine of $100 \mathrm{kHz}$ frequency modulated by the Hanning window. The size of the integration step was set as $\Delta t=5 \cdot 10^{-8} \mathrm{~s}$. The output velocity signals were recorded at selected points. Geometry of the testing 
part with positions of excitation and registration points is illustrated in Figures 4 and 5 for the plate girder and the bolted splice connection, respectively.

\subsection{ResUlTS AND DISCUSSION}

\section{The web of the plate main girder}

The conception of the use of phenomenon of guided wave propagation in the context of damage detection is based on the registration of signals and the analysis of appearing reflections. Propagating wave which reaches to the place where a change of material parameters of a medium or a border of different media occurs, is reflected. In the case of the wave excited in the plate girder, a disturbance propagates as long as it will be reflected from the connection between flanges and the plate girder. Assuming that the geometry of the testing structure as well as the group velocity of propagating wave are known, these reflections can be identified. Meanwhile, in registered signals besides expected reflections, additional pulse changes of the amplitude may occur. They can be caused by the presence of damage in the analysed part of a structure.

Visualization of the propagating wave in the form of maps of the velocity field (perpendicular to the surface of the plate) at the selected time instances is presented in Figure 6. In Figures $6 \mathrm{~b}$ and $6 \mathrm{c}$ the disturbance reflection from the notch is visible and in Figure 6f wave with much higher energy is reflected from the edges. In the case of damage with small dimensions, the differences between amplitude values reflected from edges and reflected from damage are very high. Thus, a general problem of non-destructive testing based on the phenomenon of guided wave propagation is to extract appropriate information from the signal. Individual reflections interfere with each other that cause additional problems with interpretation of results. If the notch is located closer to the edge, a risk that the reflection from it would be unnoticed without special techniques of signal processing or without checking the same damage scenario for different configurations of sensors arises.

For reflections from damage which were recorded by individual sensors the value of time-of flight can be determined. On the basis of the time-of-flight $t_{T O F}$ and the group velocity $c_{g}$ of propagating wave, the distance between the actuator (the excitation point) located at coordinates $\left(x_{A}, y_{A}\right)$, damage $\left(x_{D}, y_{D}\right)$ and the sensor (the registration point) located at $\left(x_{S}, y_{S}\right)$ can be calculated:

$$
\sqrt{\left(x_{D}-x_{A}\right)^{2}+\left(y_{D}-y_{A}\right)^{2}}+\sqrt{\left(x_{S}-x_{D}\right)^{2}+\left(y_{S}-y_{D}\right)^{2}}=t_{T O F} c_{g} .
$$


a)
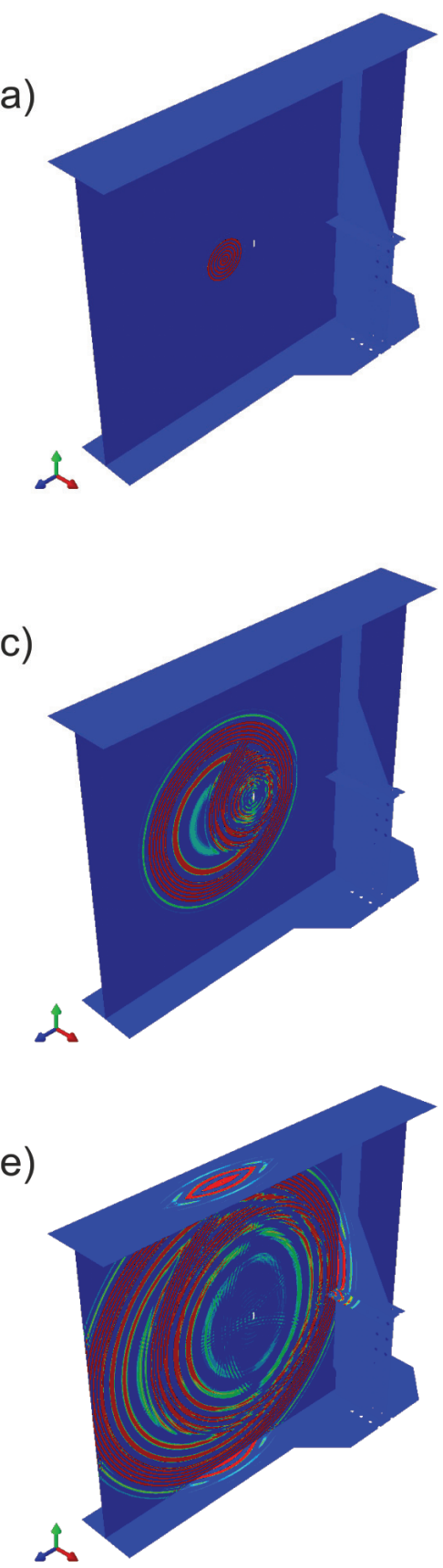
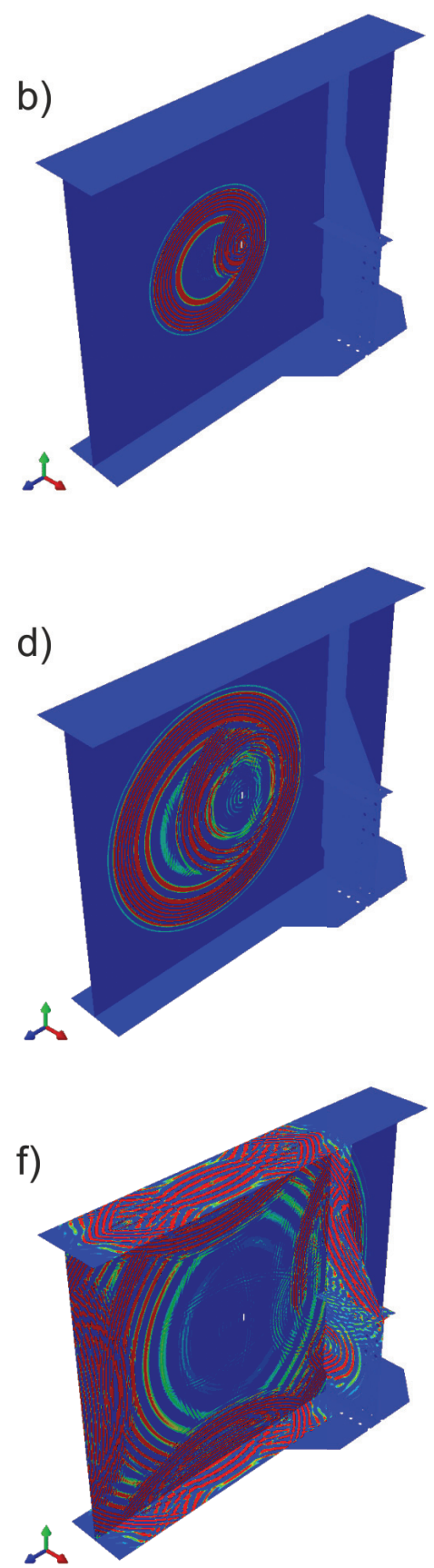

Fig. 6. Maps of velocity field propagated in plate girder at selected time instances: a) $0.05 \mathrm{~ms}$; b) $0.15 \mathrm{~ms}$; c) $0.20 \mathrm{~ms}$;) $0.25 \mathrm{~ms}$; e) $0.35 \mathrm{~ms}$;) $0.45 \mathrm{~ms}$ 
It can be noticed that the distance is equal to the sum of position vectors in the ellipse which presents all possible damage locations in a plate (Figure 7). Because from a single signal only one value of the time-of-flight can be extracted, one solution in the form of the ellipse can be plotted. To obtain accurate position of damage, at least three ellipses must intersect with each other. A simple scheme of the procedure of determining the location of damage for configuration of three sensors and one actuator is presented in Figure 8.

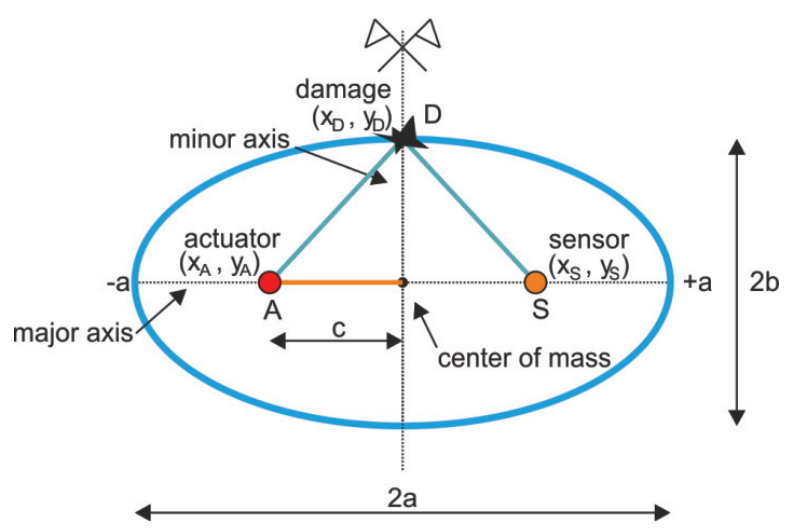

Fig. 7. Geometrical relationship between location of actuator (excitation point), sensor (registration point) and damage
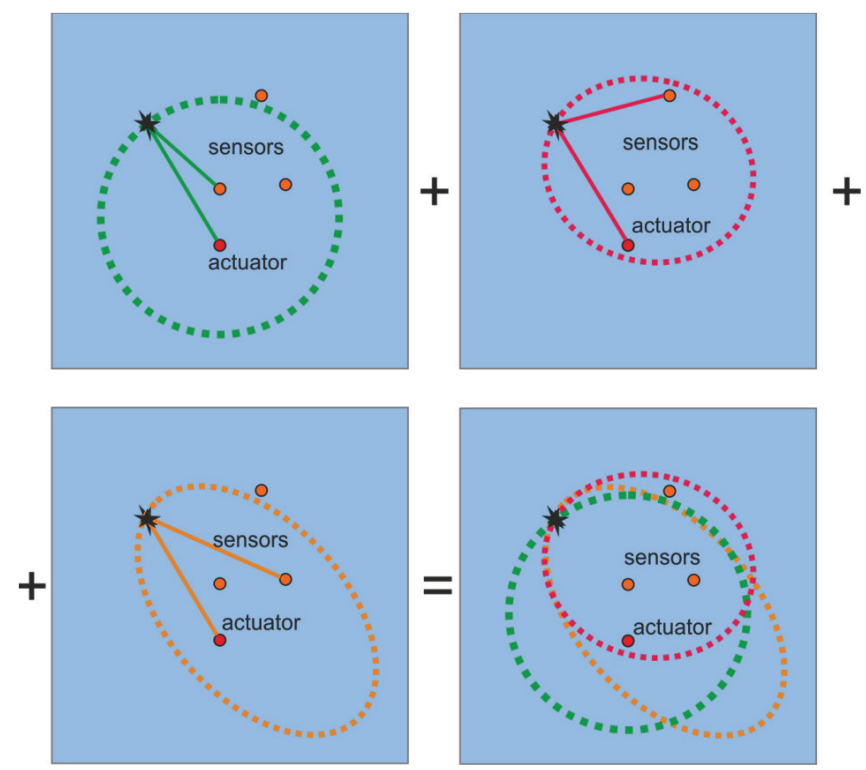

Fig. 8. Algorithm for damage detection in plate based on time-of-flight 
In numerical analyses of damage detection two configurations of sensors were applied. In configuration \#1 four PZT transducers were used: transducer no. 1 was applied as the actuator and transducers no. 3 , no. 6 , no. 8 were applied as sensors for registration of waves. In configuration \#2 nine PZT transducers were used: transducer no. 5 was applied as the actuator and transducers of numbers from 1 to 4 and from 6 to 9 were applied as sensors (cf. Figure 4). Wave propagation signals for configuration \#1 are shown in Figure 9. The reflections from the notch were identified and indicated. Then the three signals from Figure 9 were used in the procedure of creating a damage map. The damage map (Figure 10a) shows location of damage. The colours on the map are a measure of the probability of damage location in a particular place. Only these positions where all plotted ellipses intersect with each other should be taken into account as possible damage locations. Other intersection areas result from the geometrical way of solving the problem and they do not represent any characteristic feature of the testing structure.

a)

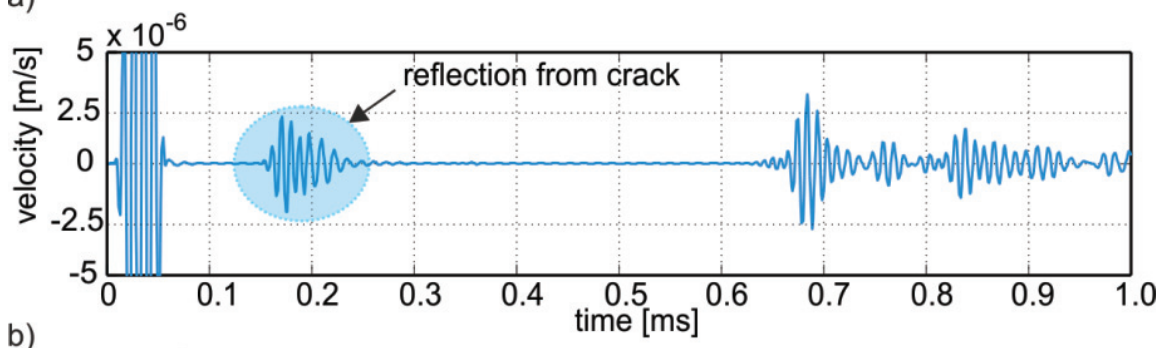

b)
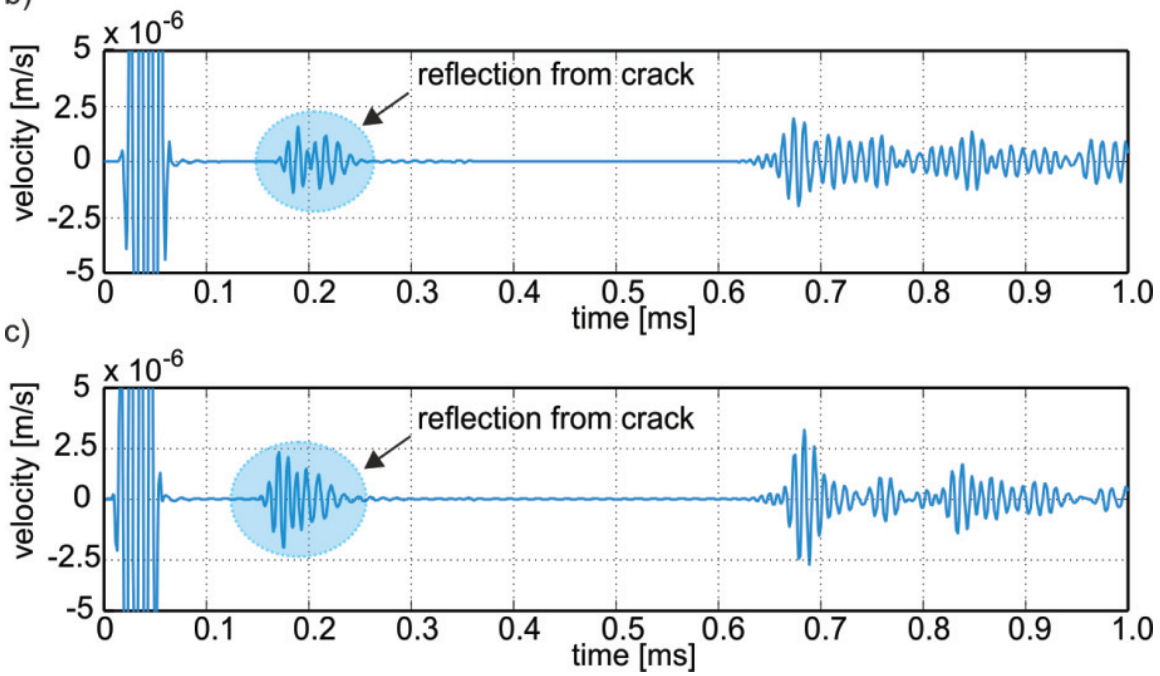

Fig. 9. Set of numerical wave propagation signals registered in plate girder by:

a) sensor no. 3, b) sensor no. 6 , c) sensor no. 8 
The sensitivity of damage localization algorithm is strictly correlated with the number of sensors and their configuration. The bigger number of signals is used during analysis, the more accurate results are obtained. To show the influence of the number of sensors which take part in investigation, the same damage scenario with another configuration of sensors (configuration \#2) was examined. The location of the excitation point was shifted from the plate centre and additional registration points were taken into account. The damage map obtained for eight signals is presented in Figure 10b. The identification of damage position is much more precise than for configuration \#1 as a result of non-symmetrical configuration of sensors and a large number of signals that were used in the process of damage map creation.

a)

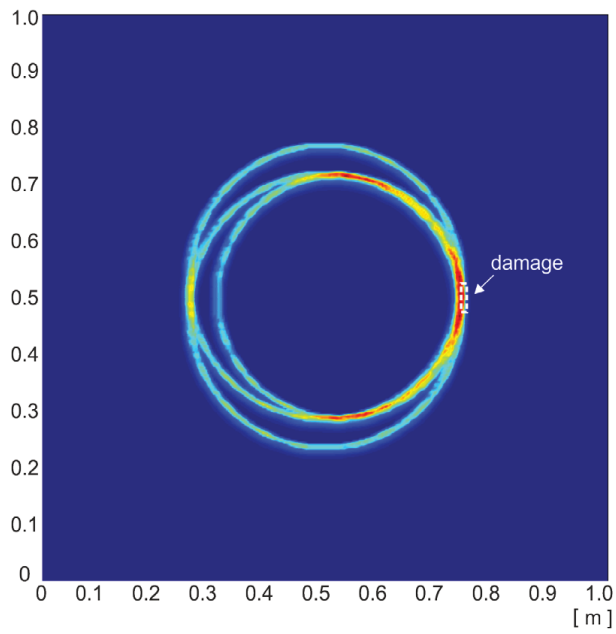

b)

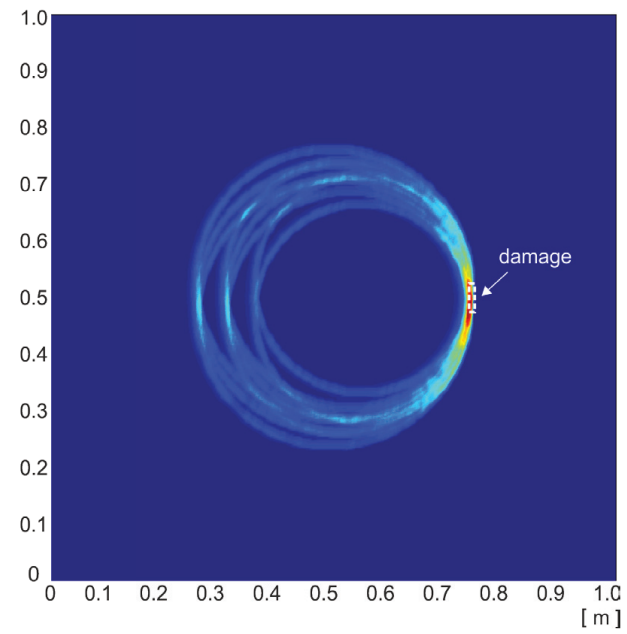

Fig. 10. Damage map for plate girder calculated on the basis of numerical wave propagation signals registered by: a) three sensors (configuration \#1); b) eight sensors (configuration \#2)

\section{The bolted splice of the cross beam}

Visualization of propagating waves in the bolted joint at the selected time instances is presented in Figure 11. The wave packet was excited in the cross beam web, near the connection with the main girder. When the wave reached the location of the connection it propagated in the overlay plates by bolts. All connection points became sources of new waves and then disturbances passed into the attached part of the cross beam. Results of numerical analyses indicated strong scattering of waves in the bolted joints area.

The examples of velocity signals received at point $\mathrm{A}$ in the case of damage absence (pristine joint) and after removing selected bolts (damage scenarios \#2 and \#3) are shown in Figure 12. There is no clear qualitative difference between obtained signals. 
a)

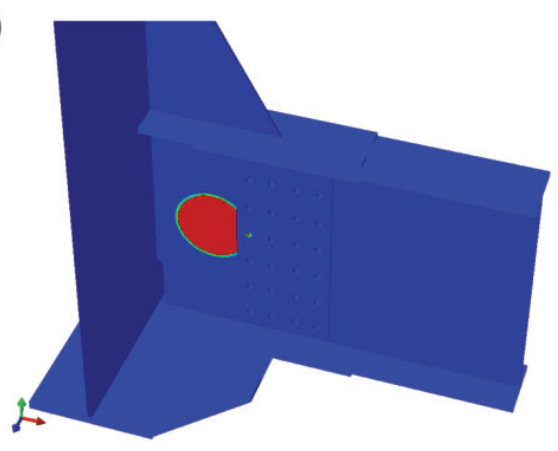

c)

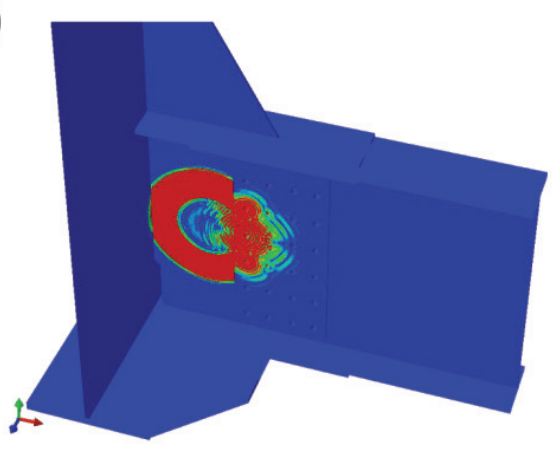

e)

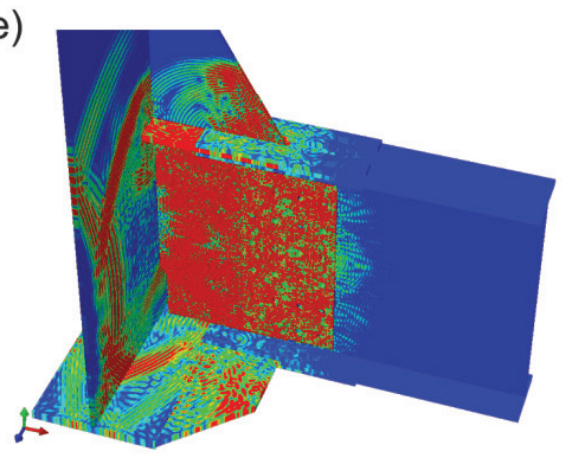

b)

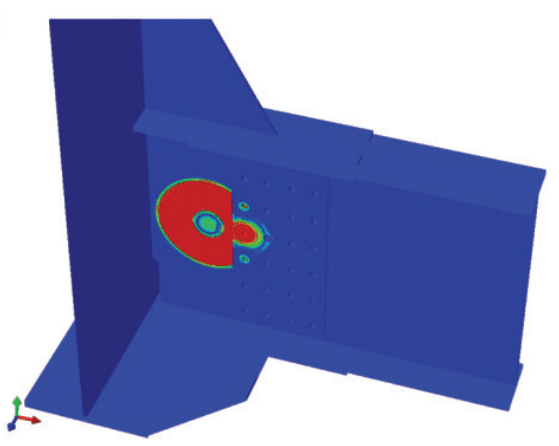

d)

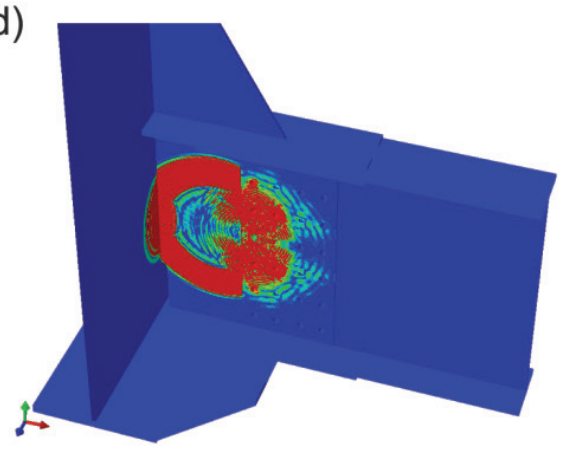

f)

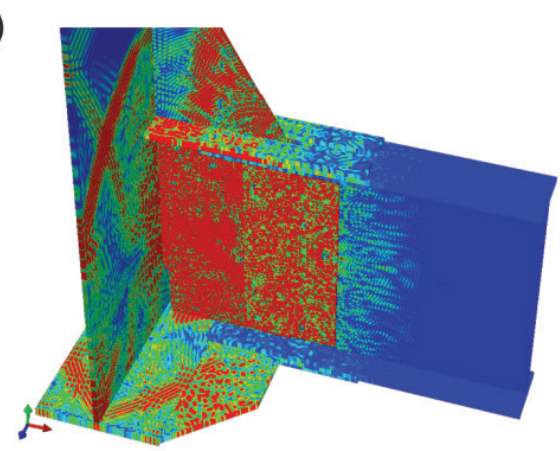

Fig. 11. Maps of velocity field propagated in bolted joint of cross beam at selected time instances: a) 0.048 $\mathrm{ms}$; b) $0.68 \mathrm{~ms}$; c) $0.88 \mathrm{~ms}$;) $0.108 \mathrm{~ms}$; e) $0.26 \mathrm{~ms}$; f) $0.32 \mathrm{~ms}$ 
In all cases in the time interval $0.21-0.35 \mathrm{~ms}$ a clearly separate wave packet can be observed. However, comparing the signal registered for damage scenario \#1 with scenarios \#2 and \#3, the decrease in signal amplitudes in the initial period of time $(0-0.35 \mathrm{~ms})$ can be seen. In order to compare the quantitative characteristics of propagated waves, energies of recorded velocity signals were determined. The signal energy $E_{s}$ in the time interval $\left\langle t_{a} ; t_{b}\right\rangle$ can be defined as:

$$
E_{s}=\sum_{i=t_{a}}^{t_{b}} x_{i}^{2}
$$

where $x_{i}$ is the signal value at the discrete time instant $t_{i}$. The values of signal energies calculated in the time interval $0-0.35 \mathrm{~ms}$ are shown in Figure 13. This interval was chosen for comparing the energy of the separated wave packet. For all cases of bolt loosening scenarios a clear decrease in the amplitude was observed. The lower energy values $(49 \% ; 29,7 \% ; 28 \%$ and $45 \%)$ were obtained when bolts lying directly on the section connecting the actuator and the sensor were removed (damage scenarios \#2, \#3, $\# 4$ and \#5, respectively).
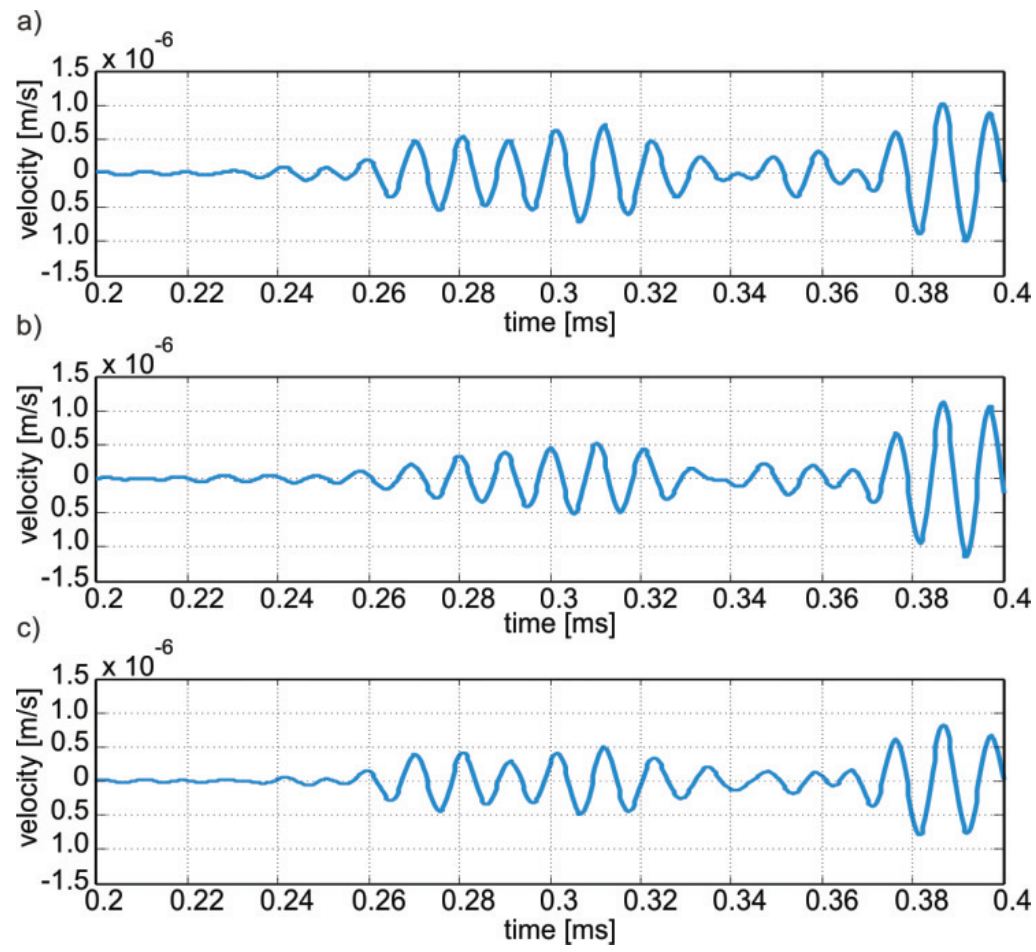

Fig. 12. Set of numerical wave propagation signals registered in bolted connection: a) damage scenario \#1 (pristine joint), b) damage scenario \#2, c) damage scenario \#3 


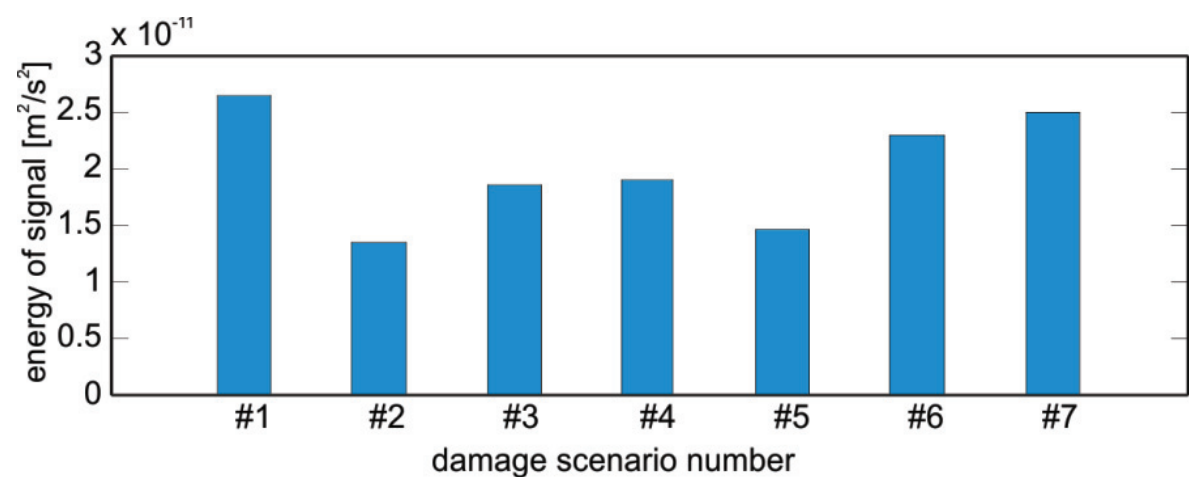

Fig. 13. Energy of numerical signals registered in bolted connection in time interval $0-0.35 \mathrm{~ms}$ for different damage scenarios

\section{EXPERIMENTAL INVESTIGATIONS}

\subsection{Plate structure}

A steel plate of length $L=1000 \mathrm{~mm}$, width $B=1000$ and thickness $d=5 \mathrm{~mm}$ was considered as a testing structure. The experimentally determined mass density $\rho$ was equal $7872 \mathrm{~kg} / \mathrm{m}^{3}$, the modulus of elasticity $E$ and the Poisson's ratio were $205.35 \mathrm{GPa}$ and 0.28 , respectively. Damage in the plate was introduced as a change of plate thickness on a rectangular area of $250 \mathrm{~mm} \times 12.5 \mathrm{~mm}$. The depth of the defect was equal to $2.5 \mathrm{~mm}$. The photo of the experimental setup is given in Figure 14. Lamb waves were generated by the piezoelectric actuator Noliac CMAP11. The excitation was in the form of a five cycle sine modulated by the Hanning window. The value of the excitation frequency was equal to $150 \mathrm{kHz}$. Velocity signals $v(t)$ (i.e. components perpendicular to the plate surface) were recorded by the scanning laser vibrometer Polytec PSV-3D-400-M. Measurements were characterized by a very high degree of repeatability.

During experiment one spatial configuration of measurement points was considered. The signal was generated at point no. 1 and sensed at points no. 1 to 10 . Almost all registration points were situated on a straight line, as it is shown in Figure 15. One point shifted from that line was required to assess the direction from which wave propagated. The difference between the value of the time-of-flight for point no. 9 and point no. 10 allowed avoiding the problem of the symmetry of results. 


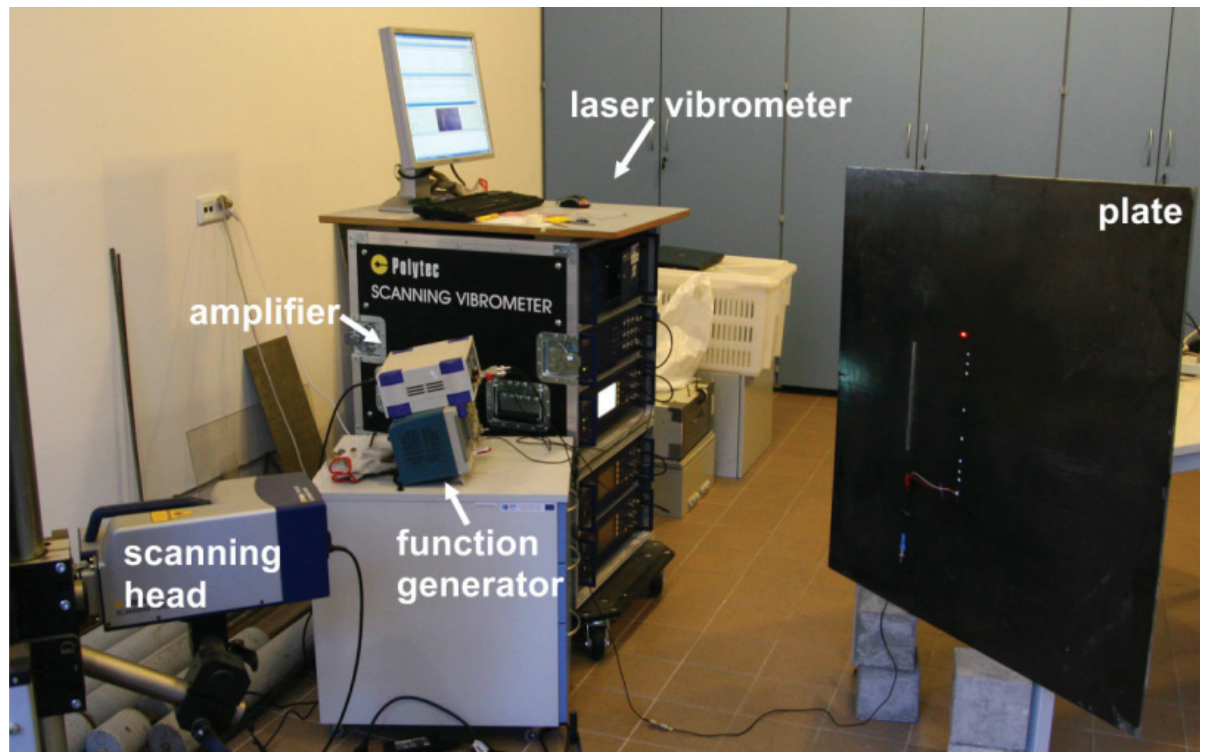

Fig. 14. Instrumentation for measurements of out-of-plane waves in steel plate

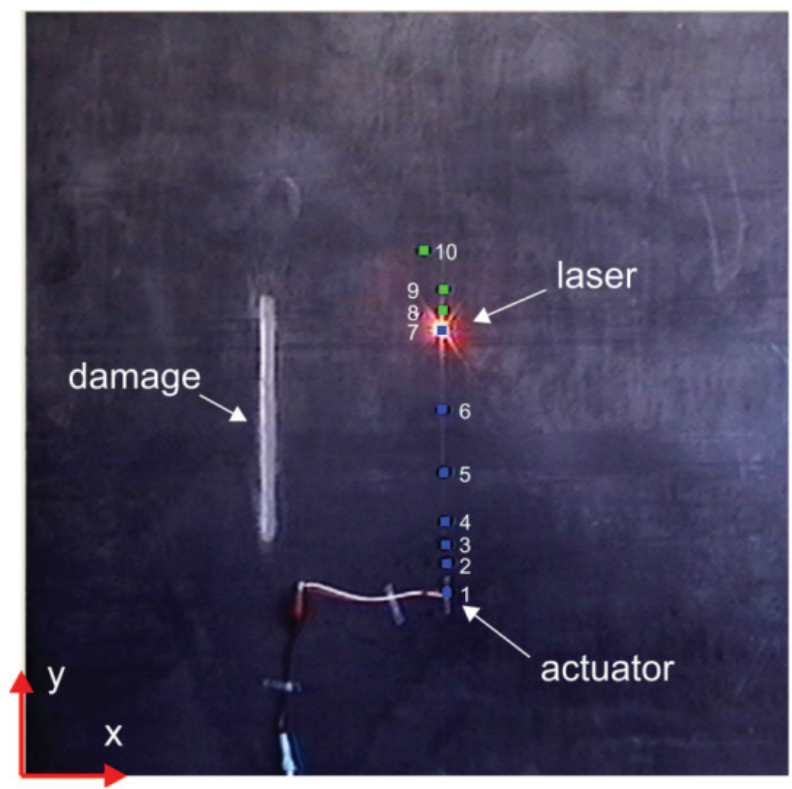

\begin{tabular}{|c|c|c|}
\hline & $\mathrm{x}[\mathrm{mm}]$ & $\mathrm{y}[\mathrm{mm}]$ \\
\hline 1 & 457.5 & 315 \\
\hline 2 & 457.5 & 345 \\
\hline 3 & 457.5 & 365 \\
\hline 4 & 457.5 & 385 \\
\hline 5 & 457.5 & 435 \\
\hline 6 & 457.5 & 500 \\
\hline 7 & 457.5 & 580 \\
\hline 8 & 457.5 & 600 \\
\hline 9 & 457.5 & 620 \\
\hline 10 & 437.5 & 660 \\
\hline
\end{tabular}

Fig. 15. Configuration of measurement points and actuator 
The examples of obtained time signals are presented in Figure 16. It is distinctly visible that reflection from damage can be detected unambiguously. On the basis of all registered signals and occurred reflections, the damage map was created (Figure 17). The obtained map is symmetrical but one shifted registration point (point no. 10) let to assess of which side of the plate the notch lies. The ellipses intersect near the one end of damage. However, for such configuration of measurement points it is very difficult to assess the exact size of the crack.

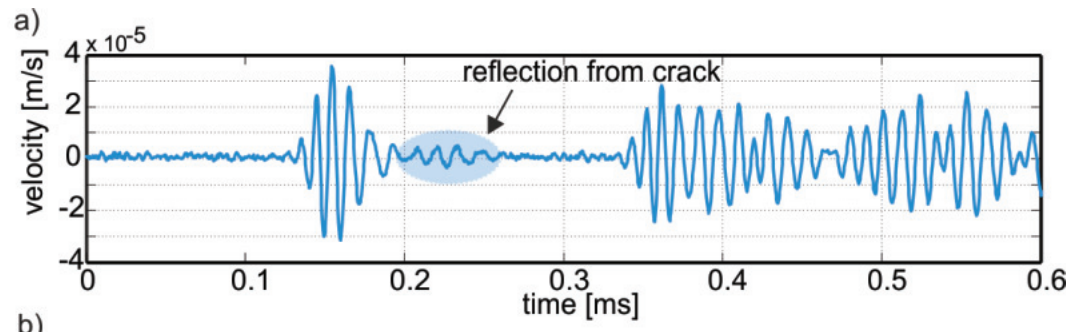

b)

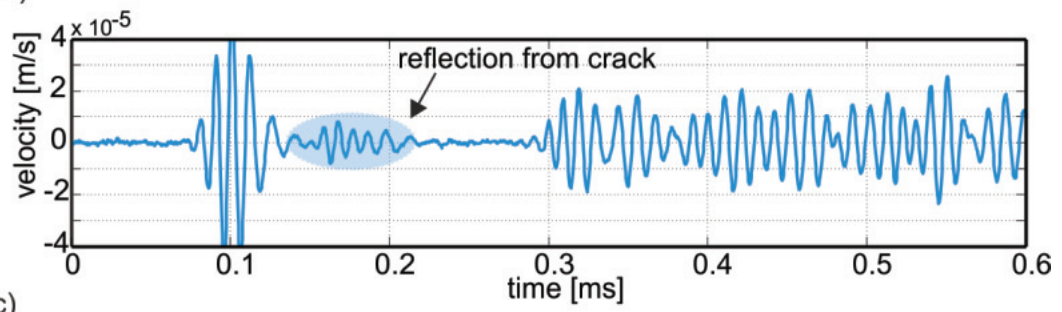

c)
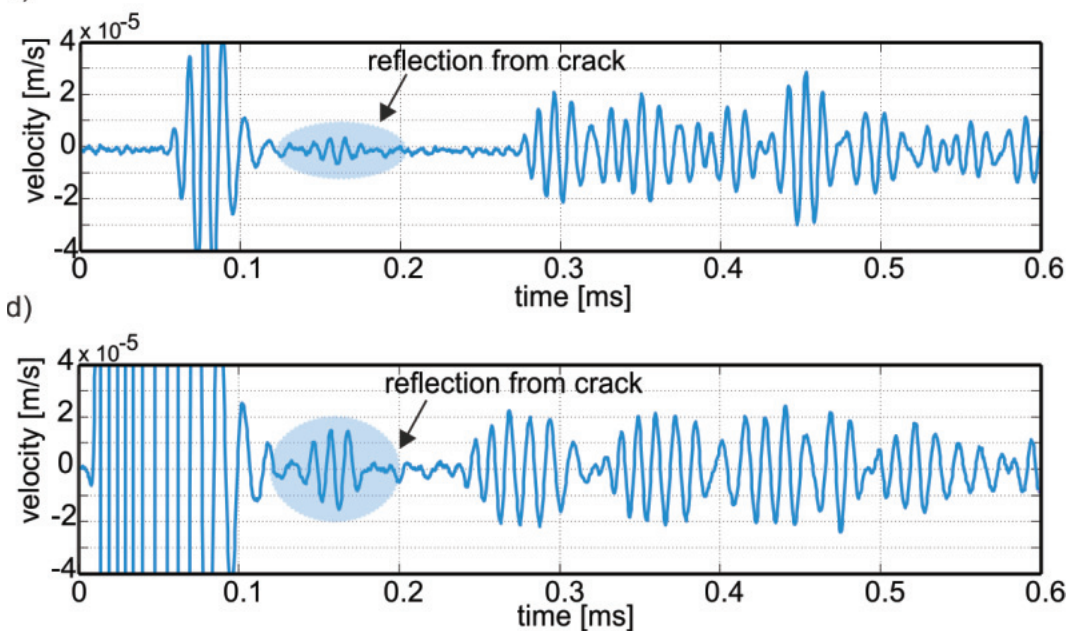

Fig. 16. Set of experimental wave propagation signals registered in steel plate: a) point no. 10; b) point no. 6 ; c) point no. 5 ; d) point no. 1 


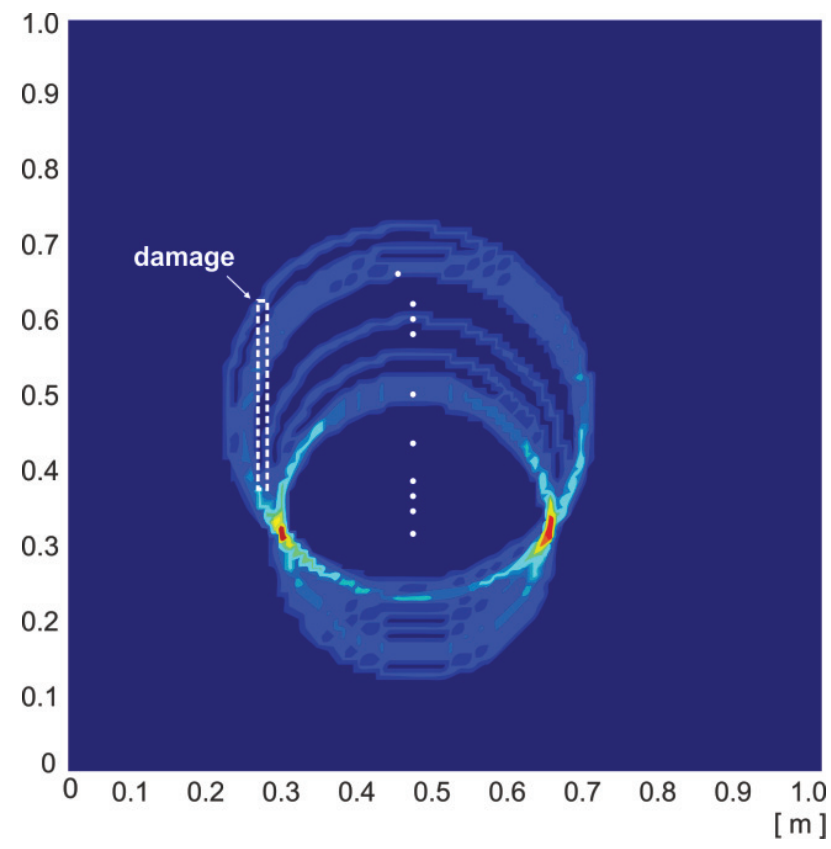

Fig. 17. Damage map for steel plate calculated on the basis of experimental wave propagation signals

\subsection{Bolted JOINT}

The research was conducted for a single lap bolted joint. It was made of two steel plates $6 \mathrm{~mm} \times 60 \mathrm{~mm} \times 200 \mathrm{~mm}$ and $6 \mathrm{~mm} \times 200 \mathrm{~mm} \times 200 \mathrm{~mm}$. In each plate four circular holes of $11 \mathrm{~mm}$ diameter were cut to assemble with the use of bolts (S1 to S4, as shown in Figure 18). Bolts of $10 \mathrm{~mm}$ diameter and $80 \mathrm{~mm}$ length were made with steel of class 8.8. The value of bolt torque moment applied to bolts with the use of a torque wrench was equal to $10 \mathrm{Nm}$. Guided waves were excited and registered in the transverse direction by PZT actuators Noliac CMAP11 of dimensions $5 \mathrm{~mm} \times 5 \mathrm{~mm} \times 2$ $\mathrm{mm}$ bonded at two side of the connection (Figure 18). The arbitrary waveform generator Tektronix AFG 3022 with the high voltage amplifier EC Electronics PPA 2000 generated the excitation voltage signal which was converted into a mechanical force by the PTZ actuator. The digital oscilloscope ScopeDAQ was used to register signals with a sampling frequency of $2 \mathrm{MHz}$. 


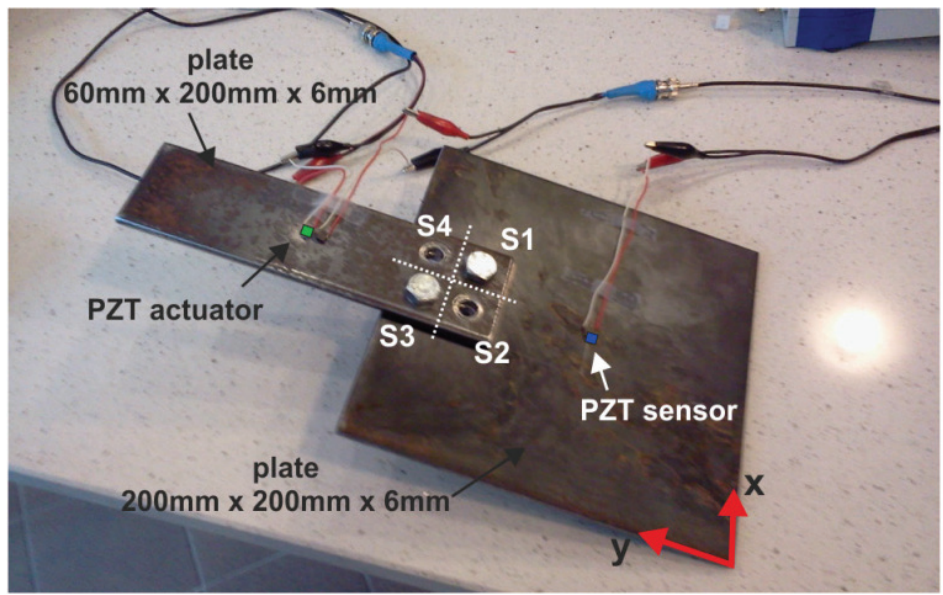

\begin{tabular}{|l|c|c|}
\hline & $x[\mathrm{~mm}]$ & $y[\mathrm{~mm}]$ \\
\hline S1 & 113 & 157 \\
\hline S2 & 87 & 157 \\
\hline S3 & 87 & 183 \\
\hline S4 & 113 & 183 \\
\hline
\end{tabular}

Fig. 18. Model of bolted lap joint and configuration of sensor and actuator

Table 3

Configuration of bolts and values of torque moments in experimental study

\begin{tabular}{|c|c|c|c|c|}
\hline \multirow{2}{*}{ Damage scenario } & \multicolumn{4}{|c|}{ Bolt torque [Nm] } \\
\cline { 2 - 5 } & $\mathrm{S} 1$ & $\mathrm{~S} 2$ & $\mathrm{~S} 3$ & $\mathrm{~S} 4$ \\
\hline$\# 1$ (pristine joint) & 10 & 10 & 10 & 10 \\
\hline$\# 2$ & 10 & no bolt & 10 & 10 \\
\hline$\# 3$ & 10 & no bolt & no bolt & 10 \\
\hline$\# 4$ & 10 & no bolt & no bolt & no bolt \\
\hline
\end{tabular}

Four damage scenarios of bolt loosening were considered (Table 3). Damage scenario \#1 was a pristine joint with four bolts. In next scenarios (\#2, \#3, \#4) one bolt (S2), two bolts (S3, S3) and three bolts (S2, S3, S4) were removed from the joint, respectively. The experimental results in the form of time signals of propagating waves for damage scenarios \#1 and \#2 are shown in Figure 19. The variation of these two signals is similar, but some qualitative changes can be observed. After removing one bolt (S2) the maximum amplitude of the signal in the time interval $0-0.3 \mathrm{~ms}$ decreased by $2 \%$. For the pristine joint the separation of the wave packet in the time interval $0.1-0.2 \mathrm{~ms}$ can be observed. However, in damage scenario \#2 this separation is not visible due to the interference of waves.

The quantitative characteristics of the output signals for different damage scenarios were determined by the calculation of signal energies (Figure 20). Comparing energies of signals in time intervals $0-0.2 \mathrm{~ms}$ and $0-0.25 \mathrm{~ms}$ for all realised damage scenarios 
a decrease in the signal energy can be observed with reference to the pristine joint. The scale of decrease was dependent on the position of the removed bolt. The results indicated that the damage index based on the energy of registered wave propagation signals gives a possibility for the state monitoring of the connection. However, it is worth noting that subsequent removing of fasteners does not always lead to a decrease in the signal energy values. It can be seen by comparing the signal energy for damage scenarios \#3 and \#4.

a)
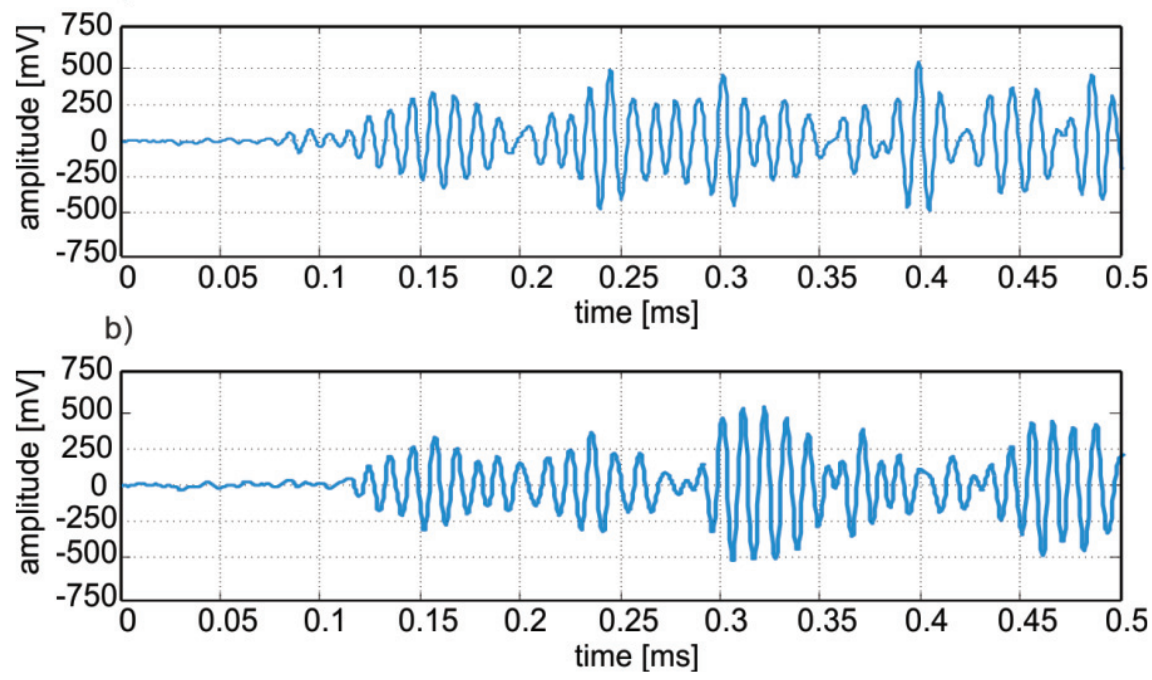

Fig. 19. Set of experimental wave propagation signals registered in bolted connection: a) damage scenario $\# 1$; b) damage scenario \#2

a)

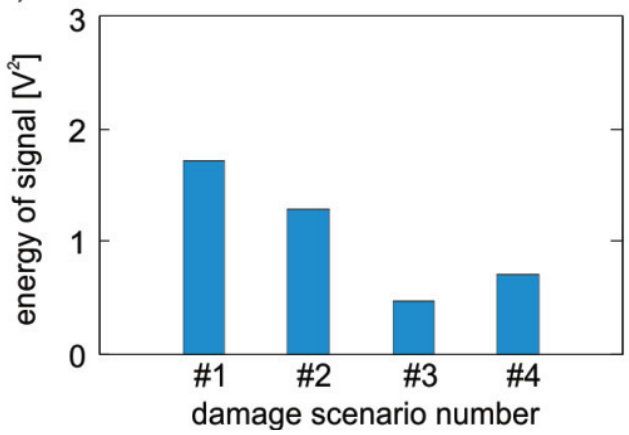

b)

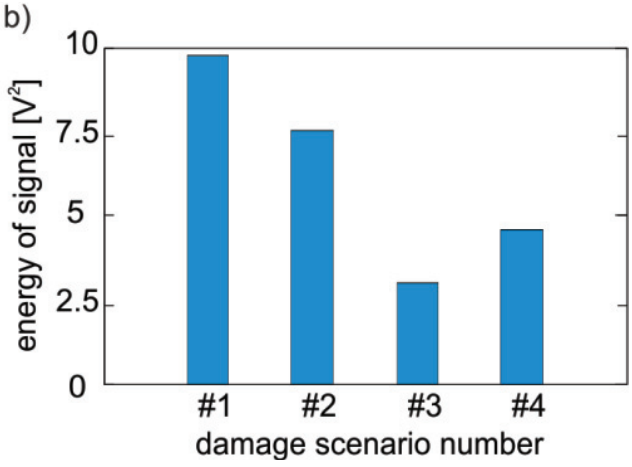

Fig. 20. Energy of experimental signals regi tered in bolted connection for different damage scenarios: a) in time interval $0-0.2 \mathrm{~ms}$; b) in time interval $0-0.25 \mathrm{~ms}$ 


\section{Conclusions}

The paper presents an application of guided wave propagation for damage detection in bridge structures. Numerical analyses were conducted on the example of a typical railway bridge. Two elements of the bridge were analysed: the plate girder and the bolted splice of a cross beam. In addition, a steel plate and a prestressed bolted joint were tested experimentally to investigate the practical application of wave propagation.

Two typical damage scenarios of the bridge girder were considered, namely damage of the plate girder because of the occurrence of corrosion and the reduction of the load capacity of the bolted splice due to the bolt loosening or fracture of fasteners in the threaded area. In the case of the plate girder, damage was considered as a long notch through the plate with a relatively small surface area in relation to the girder area. The excitation was generated in the form of a wave packet and location of damage was identified on the basis of reflections in the registered time signals of propagating waves. Damage detection in plate structures was conducted with the use of the array of sensors. Experimental and numerical analyses of wave propagation in the plate girder revealed that only appropriate configuration of piezoelectric transducers allowed creation of damage map illustrating the precise location of damage. Measurements of wave propagation in the bolted joint were performed using a single actuator-sensor system. In order to detect defects in the bolted connection quantitative characteristics of signals were used. The results indicated that the damage index based on the energy of registered wave propagation signals gave a possibility for the state monitoring of the connection. The presented method based on elastic wave propagation has a great potential in non-destructive testing of steel bridges but still must be improved with the aim to implement it in real diagnostic systems.

\section{Acknowledgements}

Calculations were carried out at the Academic Computer Center in Gdańsk.

\section{REFERENCES}

1. J. Bień, Defects and diagnostics of bridge structures (in Polish). Wydawnictwa Komunikacji i Łączności, Warszawa 2010

2. H. Wenzel, Health monitoring of Bridges, John Wiley \& Sons, Ltd., 2009

3. A. Schumacher, A. Nussbaumer, Experimental study on the fatigue behaviour of welded tubular K-joints for Bridges. Engineering Structures, 28, 745-755, 2006

4. A.M.P. de Jesus, A.L.L. da Silva, J.A.F.O. Correia, Fatigue of riveted and bolted joints made of puddle iron - An experimental approach, Journal of Constructional Steel Research 104, 81-90, 2015

5. M. Piekarczyk, R. Grec, Application of adhesive bonding in steel and aluminium structures, Archives of Civil Engineering, 58, 309-329, 2012

6. M. Rucka, Wave Propagation in Structures. Modelling, Experimental Studies and Application to Damage Detection, Wydawnictwo Politechniki Gdańskiej, Gdańsk 2011 
7. M. Rucka, Modelling of in-plane wave propagation in a plate using spectral element method and KaneMindlin theory with application to damage detection. Archive of Applied Mechanics 81, 1877-1888, 2011

8. M. Rucka, W. Witkowski, J. Chróścielewski, K. Wilde, Damage detection of a T-shaped panel by wave propagation analysis in the plane stress, Archives of Civil Engineering, 58, 3-24, 2012

9. T. Wandowski, P. Malinowski, W.M. Ostachowicz, Damage detection with concentrated configurations of piezoelectric transducers, Smart Materials and Structures, 20, 1-14, 2011

10. L. Zeng, J. Lin, Chirp-based dispersion pre-compensation for high resolution Lamb wave inspection, NDT\&E International, 61, 35-44, 2014

11. J. Esteban, C.A. Rogers, Energy dissipation through joints: theory and experiments, Computers and Structures, 75, 347-359, 2000

12. T. Wang, G. Song, Z. Wang, Y. Li, Proof-of-concept study of monitoring bolt connection status using a piezoelectric based active sensing method, Smart Materials and Structures, 22, 087001 (5pp), 2013

13. P. Seunghee, Y. Chung-Bang, R. Yongrae, Damage diagnostics on a welded zone of a steel truss member using an active sensing network system, NDT\&E International, 40, 71-76, 2007

14. J. L. Rose, Ultrasonic Waves in Solid Media, Cambridge University Press, 1999

15. EN 1993-1-8:2005. Eurocode 3: Design of steel structures - Part 1-8: Design of joints

Received: 30.08 .2014

Revised: 05.12.2014 
